\title{
Applied Research on English Speech Insertion
}

\author{
Yanping Zhang \\ School of Foreign Languages of Yulin University, Yulin, Shaanxi, 719000
}

\author{
Keywords: Insertion, English Speech, Applied Research
}

\begin{abstract}
Insert language is a common language phenomenon, it appears in a large variety of style. Because the insert itself is independent of the attached sentence in both form and content, it is regarded as an optional ingredient. So since the insert language dispensable, why does it appear in a variety of discourse? What function does it have? This study is based on this issue, using Halliday's theory of Metafunction and Adjunct to study English insertions in speech discourse, The analysis of the insert language makes a possible explanation of the deep mechanism it produces. At the same time, this article also provides a new perspective for the study of speech discourse, that is, through some of its idioms, some stylistic features of speech discourse. This article collects the outstanding award-winning lectures of 20 American college students of the same type (Persuasive). After analyzing 442 inserts among them, one can find that it is entirely possible to classify the insertions by using the three meta-functions. This also proves that Functional linguistics can analyze insertions. In the end, based on the classification of the function of the insert language, according to the concrete distribution of each type of insert language in the speech discourse, according to the occurrence frequency and ratio, it is pointed out that the insert language in the speech discourse, whether in the performance of things, Plays an important role in organizing information and interpersonal meaning, and plays different roles in reaching the effect of speech..
\end{abstract}

\section{Introduction}

It refers to a qualifying, explanatory, or appitive word, phrase, clause, or sentence occurring within a sentence in such a way as to form an interpolation independent of the surrounding syntactical structure; Bussmann Because parenthesis interrupts the continuity of both sentence construction and its meaning as a result of postponement, it causes great difficulty for both readers and translators to grasp the exact information expressed. Parentheses in English, varying in form and meaning, play an important part in communication and are found to exist in a large amount in both written and spoken English. In English public speeches, parentheses contribute to not only one key feature but one of the trouble-makers in understanding as well. The past three decades has witnessed a remarkable growth in interest towards the analysis of English written discourse, and a great deal of effort has been made to find out the factors that accompany the process of text comprehension and production. One of the fields that have been given much attention in theoretical studies and empirical investigations is the study of public speeches. Public speech refers to a continuous speech made by a public speaker before a large crowd about his systematic advocacy and propositions in spoken language. The Speaker often make use of his facial expression, signs and body gestures and the strong emotions, aiming to move, to inspire , to encourage, to persuade the listeners or even to teach them something. As an important means of communication medium in human activities, public speech derives and progresses with almost the same steps of human civilization. It is considered as an art of language and is always followed with interest by politicians, philosopher s, linguists and sociologists. In modern society, there are wide and occasion occasions calling for a public speech: a university student or teacher is asked to present his study report orally or to compete for a position; a VIP is invited to give an acknowledgement speech or an introduction on his life stories; a politician puts forward his opinion on political events, economic policy or environment protection at a seminar or college forum, and so on. So, the ability to make public speaking has been a basic ability indispensable for They must be able to introduce themselves, to show their intention, to express their feelings, and to ask for help from others. Today, with the 
development of science and technology, everything changes at a fast speed and the individuals have to meet rigid challenges one after another

\section{The proposed functional classification of English parentheses}

Parentheses fulfill the ideational functions by helping to achieve the constitution of a nominal group, for example, functioning as a post-modifier, or serving as a circumstantial adjunct. Parentheses in the shape of apposition, adjective modifier and some supplements usually play the role of helping to constitute a nominal group, while an adverbial modifier and adverbial supplements usually function as a circumstantial adjunct. An appositive is a noun or noun equivalent placed beside another noun to supplement or complement its meaning, usually set off by commas and / or dashes ( Corder, 1962). Apposition is similar with coordination in that typically the two or more units in apposition are constituents of the same level with the same grammatical function, though with different information value. Or rather, the appositive in the parenthetic form has a subordinate role in the distribution of information. Its subordinate role is exa ctly reflected in the fact that it is marked as parenthetic by intonation or punctuation (Quirk \& et al, 1980). Apposition is one of the important means to explain and complete the meaning of a noun or a nominal group, so are those adjectives and adverbials functioning as modifiers. Look at the following examples.

As the second function of language, the Interpersonal metafunction serves to make full use of language to express the relationship between people and the society. With the use of language, people communicate with others, establish and keep relationships, affect people's behaviors and express the view about the world. Some parentheses, ie the subject-predicate phrase and some adverbials, coincide with Mood adjuncts and, thus, help with the interpersonal function. What is more, some interjections and sentence fragments should also be included in the category. As put by Halliday, "Modality represents the speaker's angle, either on the validity of the assertion or on the rights and wrongs of the proposal". Adjuncts of modality fall into two groups: mood adjuncts and comment adjuncts. Mood adjuncts relate specifically to the meaning of the finite verbal operators, expressing possibility / obligation, usual, presumption (evidently, apparently, clearly), and so on. These mood adjuncts are typically occurring next to the finite, either before it or after it. Comment adjunct, as far as its position in the clause is concerned, they tend to occur thematically between theme and rheme, or between Mood and Residue, and when medial, they are typically associated with a boundary between information units. The types of comment adjuncts are admissive, assertive, presumptive, desiderative, validative and so on.

There are four ways by which cohesion is created in English: by reference, ellipsis, conjunction and lexical organization. Textual parentheses, as a cohesive means, just belong to the third type conjunctions. Functionally, textual parentheses tend to cover conjunctive adjuncts and some other conjunctions and some adverbials. Conjunctive elements refer to those transitional words and expressions, which show the logical relations of cause and effect, condition, concession, comparison and contrast, etc. Conjunctions can be found in clauses, between clauses, and between clause and sentence. Conjunction is a crucial element in cohesion and coherence. What we ought to do is to find out how it offers in individual texts and how it works together with other cohesive devices. They indicate cohesion by means of showing Here, we shall follow the scheme o proposed by Halliday (1985), which is founded on the logico-semantic relations represented. Comparing with his former system of four categories advanced in cohesion in English, the new method is everything but simplification Though it seems that fewer categories are listed, more sub-categories are further divided under the heading of each category.

\section{Functions of parentheses in public speeches}

As can be seen from the above table, a large proportion of parentheses in public parentheses, a percentage as high as more than $27 \%$, are ascribed to the textual category. Therefore, the second largest role of parentheses in public speaking is to function as cohesive means to make the text 
cohesive and logical. The conjunctive relations realized by these parentheses cover all the three major categories classified by Halliday on the basis of his former studies: elaboration, extension, and enhancement. A successful public speech must be well organized. This has been been confirmed by careful researches that has established three conclusions about speech organization. The study by Ernest C. Thompson (1960) demonstrated that an audience that listens to an organized speech understands it much better than if the speech is not organized. Another experiment (Sharp and Mc Clung, 1966) established the interesting fact that when a speech was well organized, then the audience considered more the speaker as more confident and trustworthy. Greene (1984) found that speakers reported that they were more comfortable in speaking when their speeches were more organized than they did when they were less organized So after has determined the points contained in the speech, the next significant step is to properly arrange and organize the selected points in such a sequence that they can best accomplish the general and specific purpose of the speech. There are many different ways in which In a way of speech can be organized. are dealt with separately here, but it does not mean that every time a textual parenthesis can only perform one pattern exclusively within one speech. It is meaningful to point out that several items can convey different conjunctive relationship when placed in different context, such as to usually communicate a causal-conditional relation; it can also be used as indicator of apposition and manner. Still can also express causal-conditional relation as well as an adversative one. In this study, the author is going to category this kind of items according to the functions they play in the concrete context.

Parentheses can serve to organize the points in order and process. The category of temporal parentheses makes up the greatest proportion in Textual Parentheses, which is consistent with the fact that a chronological pattern is very commonly used in arranging and organizing points in public speeches. In a public speech, the points or ideas of a public speech are usually arranged in time order or a one-after-another process, in other words, points in public speeches are put in the order in which they occur or occurred (Lucas, 2006 This pattern is preferable when the subject matter involves a time sequence or one-after-another process, or when the speaker want to instruct people how to do something, or to explain people how things develop in a consecutive way, or even to introduce a new topic and make a conclusion. The process may be either specific or abstract. It is commonplace to use ordinal numbers in public speech as cohesive means link in the following examples. They link the points together and clearly demonstrate their sequential order as well.

The last function of Textual parentheses in a persuasive public speech is elaboration which is subdivided into two subcategories, namely apposition and clarification. Among the items which occur in the public speeches collected, for example / instance (also include as an example), the most frequently one carries the exemplificatory sense, while in other words express the expository sense which can indicia and annotation. As shown in table 5.2, the first category, elaboration contains least parentheses, with 8 items, 31 occurrences and 24\% percentage of all. Of the two categories, including apposition and clarification, the former one has 3 items, with the frequent occurrences 13; and the latter latter clarification has 5 items, with 7 occurrences. The subcategory of clarification includes seven kinds, corrective, distractive, dismissive, particularizing, After we have analyzed the data, we find that, in the 7 low frequently used Textual Parentheses, the following 3 subcategories are currently: summative, verifactive, and corrective ones. In short and in a word are summative , with 2 total occurrences; as a matter of fact and in fact are verifactive, 2 occurrences totally; rather is corrective, 3 occurrences. The subcategory of clarification involves the correction of the wording, as rather, and also the correction of meaning as in fact and as a matter of fact. The former type is related to the bordering on the expressed sense, and the latter type 'as against what you might expect, the fact of the matter is ...' Both take the form of an assertion of veracity, and contribute to the clarification of the expression. The summative parentheses are the reverse of internal previews. Rather than letting listeners know what is coming up next, i nternal summaries remind listeners of what they have just heard. Such summaries are generally used when a speaker finishes a complicated or particularly important main point or set of main point. 


\section{Conclusion}

Drawing on SFG (Systemic Functional Grammar) and the theory of Adjunct proposed by Halliday, this thesis for started out to analyze English parentheses from a functional perspective. The data for analysis come from the commonest means of communication - public speeches, which incorporate the characteristics of both spoken English and written English. Through the analysis of 442 parentheses from 20 persuasive public speeches made by 20 young American college students, some findings and conclusions are reached.

\section{References}

[1] Zhang Weina. A Preliminary Study on English Listening and Speaking Teaching Based on English Speech [J]. China Building Materials Science. 2017 (04)

[2] Chu Jin. On how to improve the level of secondary school students' English speech [J]. China Out-of-school Education. 2017 (25)

[3] Huang. Discussion on the Teaching Model of College English Lecture under Constructivism [J]. Chinese Journal of Education. 2015 (S1)

[4] Wang Huali. Situationalization of English speech writing [J]. Curriculum Education Research. 2017 (27)

[5] Hu Rong. On TSE Training Mode of Impromptu Speech in College English Speaking Contest [J] .Journal of Campus English. 2017 (29)

[6] Huang Tao, Lu Wenyue. Speech · Text · Rhetoric · Effectiveness: Some Rhetoric Tendency in Chinese College English Speeches [J]. Foreign Language Education in Art. 2010 (02)

[7] Gong Chenfeng, Liu Ying. On the English speech teaching in the English guide training in the use of [J]. Zhejiang Tourism Institute of China. 2006 (01) 